\title{
VISÃO DAS MÃES EM RELAÇÃO AO CUIDADO COM O RECÉM-NASCIDO APÓS A ALTA DA UTI NEONATAL
}

\section{Daiane Cristina Moderno Estevam}

Centro Universitário Cesumar (UniCesumar), Maringá (PR), Brasil

E-mail: dai_cris.estevam@hotmail.com

Juliana Dalcin Donini e Silva

Coordenadora no Centro Universitário Cesumar (UniCesumar), Maringá (PR), Brasil.
RESUMO: Atualmente o número de internações de recém-nascidos em Unidade de Terapia Intensiva Neonatal (UTIN) tem sido relevante. Ao receberem alta para a Unidade Pediátrica as mães vivenciam sentimentos positivos e negativos relacionados à responsabilidade de cuidar do filho ainda em tratamento e preparar-se para a alta hospitalar. O estudo objetivou desvelar a visão das mães em relação ao cuidado com o recém-nascido durante o período de internação em Unidade Pediátrica, após alta da UTIN. Trata-se de uma pesquisa descritiva e exploratória com abordagem qualitativa. Foram entrevistadas cinco mães maiores de dezoito anos e com filhos menores de um ano, sendo que todas passaram pela experiência de terem seus filhos internados logo após o nascimento em uma UTIN e, após, receberam alta para uma Unidade Pediátrica. A partir da análise dos depoimentos, revelaram-se três categorias: a vivência dos primeiros momentos com o filho após a alta da UTIN; a percepção da mãe em relação aos cuidados prestados pela equipe de enfermagem na unidade pediátrica; e experienciando o momento de ir para casa. As mães desvelaram sentimentos de angústia, medo, impotência, alívio, alegria e satisfação frente ao cuidado. Assim observamos a importância do gerenciamento da assistência de enfermagem, realizada pelo enfermeiro com o intuito de orientar e capacitar as mães para o cuidado com o filho após a alta da Unidade Pediátrica. Sendo assim, buscamos instrumentalizar os profissionais enfermeiros com o intuito de contribuir para o processo de humanização da assistência de enfermagem.

PALAVRAS-CHAVE: Alta Hospitalar; Assistência de Enfermagem; Humanização; Unidade de Terapia Intensiva Neonatal.

\section{MOTHERS' PERSPECTIVE ON THE CARE OF NEWLY- BORN CHILDREN AFTER DISCHARGE FROM NEONATAL ICU}

\begin{abstract}
The number of current hospitalizations of newly-born infants in Neonatal Intensive Therapy Units (NITU) is currently high. When the children are discharged from NITU, the mothers experience positive and negative feelings related to the responsibility of taking care of their children still under treatment and preparing themselves for total hospital discharge. Current analysis investigates the perspective of mothers with regard to the care of the newly-born during this period in the Pediatric Unit (PU) after discharge from NITU. The descriptive, quality and exploratory research comprised interviews with five over eighteen-year-old mothers with less than one-year-old children, who had their children hospitalized immediately after birth in NITU, coupled to a later stay at the Pediatric Unit. Interviews revealed three categories: experience of the first instances with the child after discharge from NITU; the mother's perception with regard to care
\end{abstract}


provided by the nursing team in the PU; experiencing the moment of returning home. Mothers revealed feelings of anxiety, fear, impotence, relief, happiness and satisfaction in the wake of care given. The administration in nursing to give guidance and capacity to mothers for child care after discharge from the PU is highly relevant. Nursing professionals should be capacitated to contribute towards the humanization of nursing assistance.

KEYWORDS: Discharge from Hospital; Nursing Assistance; Humanized Birth; Neonatal Intensive Therapy Unit.

\section{INTRODUÇÃO}

As internações de recém-nascidos em Unidades de Terapia Intensiva Neonatal (UTIN) vêm aumentando gradativamente por uma série de causas como a prematuridade, as más formações congênitas, as infecções, desconfortos respiratórios, entre outras.

Atualmente os grandes avanços técnicocientíficos contribuem para o aumento da sobrevida de recém-nascidos (RN) (GAIVA, 2006); para tanto torna-se essencial que o desenvolvimento de educação continuada em enfermagem acompanhe este desenvolvimento de modo que a equipe prepare a família para o cuidado de seu filho no momento da alta.

Quando se gera um filho prematuro, gera-se também uma mãe prematura, e a família se depara com uma realidade paradoxal, surgem sentimentos contrários ao esperado, que são difíceis, muitas vezes, de serem compreendidos por nós, enquanto profissionais da saúde (SALES et al., 2006).

Quando uma criança, ao nascer, necessita de assistência na UTIN, a mãe passa a ser mera expectadora dos cuidados especializados que são prestados ao seu filho pela equipe de saúde. O cenário repleto de profissionais especializados, luzes, fios, aparelhos, incessante estimulação sonora por diversos alarmes e ruídos ensurdecedores, produz sentimento de incerteza e insegurança na mãe em relação à vida de seu filho fora daquele ambiente (ARAÚJO; RODRIGUES, 2010).

Durante a internação do RN na UTIN há um distanciamento entre o binômio mãe/filho, pois este, muitas vezes, encontra-se rodeado de aparelhos e restrito à manipulação excessiva, e quase sempre por um período prolongado. Ao receber alta da UTIN, este bebê é transferido para o setor de pediatria, para dar continuidade ao tratamento, restabelecer o vínculo materno e oportunizar à mãe o aprendizado referente aos cuidados que deverão ser dispensados ao bebê a partir deste momento.

As mudanças que ocorrem com a mãe no período de internação de seu filho sinalizam para a necessidade de um cuidado direcionado a elas, permitindo inferir que as ações não se limitam ao recém-nascido. Desta forma, pode-se dizer que a presença da mãe reconfigura as necessidades de saúde tanto do bebê, quanto dela própria, durante a hospitalização, ocasionando a necessidade de se estabelecerem novas relações das mães com a equipe de enfermagem para uma edificação simultânea de condições que poderão ser favoráveis para o cuidado dessas crianças (DUARTE; SENA; XAVIER, 2011).

Partindo do pressuposto de que o bebê e sua família são o centro da assistência, podemos inferir a importância do cuidado da criança em parceria com a mãe, sendo primordial o reconhecimento, por parte da equipe de enfermagem, quanto às diferenças existentes na perspectiva do olhar da mãe, que, associado ao fazer profissional, podem favorecer a integralidade da assistência. A partir da vivencia das mães, profissionais e bebês, é possível, utilizando-se dos diferentes olhares, a produção de um cuidado integral e humanizado ao binômio mãe/filho (DUARTE; SENA; XAVIER, 2011).

De acordo com a problemática descrita e da experiência vivenciada em cuidados a crianças no setor de pediatria pela pesquisadora deste estudo, observase o grande desafio enfrentado pelas mães perante a necessidade em aprender a cuidar de seu filho, assim como a proximidade do momento de levá-lo para casa, levando-os a sentimentos de medo e conflito pessoal frente a cuidados tão específicos.

Sendo assim, objetiva-se, por meio deste estudo, desvelar a visão das mães em relação ao cuidado com o recém-nascido durante o período de internação em unidade pediátrica, após alta da UTIN.

\section{METODOLOGIA}

Trata-se de uma pesquisa descritiva e exploratória com abordagem qualitativa. 
A pesquisa exploratória tem como objetivo proporcionar maior familiaridade com o problema, com vistas a torná-lo mais explícito ou constituir hipóteses. Pode-se dizer que estas pesquisas têm como objetivo principal o aprimoramento de ideias ou a descoberta de intuições. Seu planejamento é, portanto, bastante flexível, de modo que possibilite a consideração dos mais variados aspectos relativos ao fato estudado (GIL, 2010).

Sendoque a pesquisa descritiva tem comoobjetivo primordial a descrição das características de determinada população ou fenômeno ou, então, o estabelecimento de relações entre variáveis, normalmente são utilizadas, juntamente com as exploratórias, as que habitualmente realizam os pesquisadores sociais preocupados com a atuação prática (GIL, 2010).

$\mathrm{Na}$ abordagem qualitativa a pesquisa não se baseia em um conceito teórico e metodológico unificado. Diversas abordagens teóricas e seus métodos caracterizam as discussões e a prática da pesquisa (FLICK, 2009).

Deste modo, constituíram sujeitos do estudo cinco mães de bebês que foram internados em UTIN e após a alta permaneceram em unidade de internação pediátrica.

Os critérios de inclusão para participação do estudo foram: mães maiores de dezoito anos de idade que acompanharam seus filhos recém-nascidos durante internação em UTIN e unidade de internação pediátrica e que, atualmente, realizam acompanhamento dessas crianças na clínica pediátrica escolhida para a seleção das depoentes; a idade das crianças deveria ser de um ano ou menos no dia da entrevista.

O local escolhido para seleção das mães foi uma Clínica Pediátrica localizada na cidade de Maringá - Paraná.

Para efetivação do estudo foi realizado, inicialmente, um levantamento bibliográfico onde foram utilizados livros disponíveis no acervo da biblioteca do Centro Universitário Cesumar (UniCesumar), revistas científicas e bases de dados on-line como Lilacs, Scielo (Scientific Electronic Library Online), BDENF.

Mediante autorização do local, o projeto foi encaminhado ao Comitê de Ética e Pesquisa (CEP) do UniCesumar para apreciação e emissão de parecer.

Após aprovação do projeto pelo CEP, de acordo com o parecer $\mathrm{n}^{0} 767.561$, os dados de identificação e telefone das possíveis participantes foram coletados na Clínica Pediátrica. Posteriormente foi realizado contato telefônico, onde foram brevemente expostos os objetivos da pesquisa. Perante a aceitação da participação no estudo, foi agendado data, horário e local de preferência dos sujeitos para realização das entrevistas. A coleta de dados foi realizada no período de 01 de setembro a 06 de outubro de 2014.

Em dia e hora marcados, foi apresentado o Termo de Consentimento Livre e Esclarecido, que após leitura e compreensão, foi assinado pela depoente e pesquisador em duas vias, sendo uma delas entregue à participante $\mathrm{e}$ outra arquivada.

Os dados foram obtidos através da realização de entrevistas orientadas por um questionário semiestruturado composto por dados de identificação e questões norteadoras elaborados especificamente para este estudo. Diante da autorização das depoentes, as entrevistas foram gravadas e posteriormente transcritas na íntegra, garantindo a fidelidade dos depoimentos.

Depois de transcritas, as falas foram meditadas, categorizadas e analisadas pelo método de análise de conteúdo de Bardin, que consiste em um conjunto de conteúdo das mensagens, indicadores (quantitativos ou não) que permitiram as técnicas de comunicações, visando obter, por procedimentos sistemáticos e objetivos de descrição, inferência de conhecimentos relativos às condições de produção, recepção (variáveis inferidas) destas mensagens.

A análise por categorias é, cronologicamente, a mais antiga e a mais utilizada no conjunto das técnicas da análise de conteúdo. Funciona por operações de desmembramento do texto em unidades, em categorias segundo reagrupamentos analógicos. Entre as diferentes possibilidades de categorização, a investigação dos temas, ou análise temática, é rápida e eficaz na condição de se aplicar a discursos diretos (significações manifestas) e simples (BARDIN, 1978).

Destaca-se que foram respeitados todos os princípios éticos e legais estabelecidos pela Portaria $\mathrm{n}^{\circ}$ 466/2012 do CNS/MS. 


\section{RESULTADOS E DISCUSSÃO}

Entre as depoentes a faixa etária variou entre 23 e 41 anos, uma solteira e as demais casadas. Em relação à escolaridade, uma tem ensino médio completo, duas possuem ensino superior completo e duas são pósgraduadas.

De todas as mães apenas uma já tinha um filho e uma foi mãe de gemelar, sendo que ambos permaneceram hospitalizados na UTIN e receberam alta em períodos distintos.

No que diz respeito à idade gestacional, esse dado variou entre 31 semanas e 37 semanas e 4 dias. Os motivos das internações dos RNs na UCIN foram dois por prematuridade, um por prematuridade associada a Desconforto Respiratório, um associado a infecção hospitalar e um por Atresia de Esôfago. O tempo de permanência na UTIN variou entre dois e sessenta dias, e o tempo de permanência na Unidade Pediátrica foi de dois a-quatorze dias de internação.

De forma a manter o sigilo e preservar os nomes das depoentes, optou-se por identificá-las por nome de flores pois transmitem a beleza da maternidade e celebram a vida. Os nomes escolhidos foram Margarida, Rosa, Tulipa, Primavera e Orquídea, mantendo a feminilidade.

Após transcrição e meditação das entrevistas, revelaram-se três categorias que desvelaram a visão das mães em relação ao cuidado com o recém-nascido após a alta da UTIN, descritas a seguir: a vivência dos primeiros momentos com o filho após a alta da UTIN; a percepção da mãe em relação aos cuidados prestados pela equipe de enfermagem na unidade pediátrica; e experienciando o momento de ir para casa.

\subsection{A VIVÊNCIA DOS PRIMEIROS MOMENTOS COM O FILHO APÓS A ALTA DA UTIN}

No relato de Rosa ficam explícitos a ansiedade e o medo de que algo poderia ter dado errado durante a internação do filho na UTIN:

Você fica bem angustiada com o estado que fica na UTI, mesmo que não esteja em estado grave, porque as pessoas falam que UTI às vezes você está com uma coisinha simples e pode complicar [...] (Rosa).
Durante a internação do filho na UTIN, as mães experimentam sentimentos advindos do rompimento do binômio mãe/filho, pois além do RN estar suscetível a procedimentos invasivos, dor e sofrimento, o ambiente é inóspito e percebido como ameaçador diante dos procedimentos invasivos. Os sentimentos da mãe são de incerteza e insegurança por ver seu filho sendo submetido a procedimentos traumatizantes (RODRIGUES; MOREIRA, 2012).

Após a alta do bebê da UTIN, diante das expectativas da nova fase, a mãe experimenta sentimentos que podem ser positivos, negativos ou simultâneos.

As depoentes deste estudo relatam uma mistura de medo, alegria, angústia, alívio e dúvidas diante de mais uma etapa a ser vivenciada com o filho, agora na Unidade de Internação Pediátrica.

Geralmente, a transferência do bebê da UTIN para a Unidade de Internação Pediátrica ainda é acompanhada por aparelhos, sondas e dispositivos intravenosos, e esses contribuem para a sensação de medo e preocupação, pois a mãe, muitas vezes, não se encontra preparada para vivenciar este momento.

$$
\begin{aligned}
& \text { Foi uma sensação tipo de impotên- } \\
& \text { cia, ao mesmo tempo que eu tava } \\
& \text { feliz com a situação eu tava preocu- } \\
& \text { pada, porque a partir daquele mo- } \\
& \text { mento ela era minha, e assim, era } \\
& \text { um medo muito grande, por que } \\
& \text { ela veio ainda com CAT no pescoço, } \\
& \text { tinha todo um aparato, muitos apa- } \\
& \text { relhos né, eu fiquei assim um pouco } \\
& \text { preocupada com sonda, então foi } \\
& \text { todo um processo. Então assim, ao } \\
& \text { mesmo tempo que eu fiquei muito } \\
& \text { feliz com a alta dela, eu fiquei com } \\
& \text { muito medo, por que [...] era uma } \\
& \text { situação assim pra mim muito dife- } \\
& \text { rente (Tulipa). }
\end{aligned}
$$

Este sentimento de impotência da mãe pode estar vinculado à fragilidade do RN, e esse momento ainda pode representar o risco de perda, gerando insegurança e angústia (ANJOS et al., 2012).

Logo, também há uma preocupação constante em relação à continuidade do tratamento, como será o desenvolvimento do bebê e a recuperação, assim como a possível necessidade de retornar à UTIN. Essas incertezas são observadas no relato a seguir: 
Foi um alívio receber alta da UTI, mas ao mesmo tempo pra mim foi bem preocupante porque como ele saiu bem desnutrido, ele não mamava sozinho, então ficava ainda com aquela sonda gástrica, então meu maior medo era ele não conseguir mamar e ter que ficar com aquela sonda muito tempo, porque aquilo também causa infecção (Primavera).

Por outro lado, diante da notícia de que o RN recebeu alta da UTIN para a unidade de internação pediátrica, as depoentes revelam grande satisfação.

Destarte, outros autores também identificaram estes sentimentos positivos de alegria, gratidão e alívio ao receber o bebê fora de risco de vida, um momento tão esperado que havia sido adiado em função das circunstâncias inesperadas (SOUZA; SILVA; GUIMARÃES; 2008).

O sentimento foi de alívio [...] foi de alivio porque daí a gente foi pro quarto juntas, ela não veio pra casa porque estava tomando a medicação. Aí foi um alivio né, porque eu sabia que ela já tava estava bem já né, porque daí eu sabia que ela só precisava ganhar peso pra vim embora (Margarida).

Pode-se apreender que esse momento tão esperado de cuidar do bebê representa para a mãe a oportunidade de executar tarefas aprendidas; configurase em um verdadeiro exercício de conhecimento e reconhecimento de seu filho, um instante único de aceitação e ligação afetiva (ARAÚJO; RODRIGUES, 2010).

A expectativa da alta do RN da UTIN para a Unidade Pediátrica é intensamente expressada pela mãe que, ao compartilhar este sentimento, demonstra um olhar de grande satisfação e um discreto sorriso.

Eu já estava aguardando, ansiosa né! A expectativa é que ficaria pouco tempo ali, mais pra observação. Foi mais por este fator da prematuridade mesmo, então ele ficou pouco tempo lá. Eu já tava ansiosa pra ele sair, quando ele saiu e foi pro quarto eu já estava lá! É isso aí (Orquídea).

Para a mãe, o período de espera entre a internação do filho recém-nascido na UTIN e a alta para o quarto é tremendamente longo, visto que o sonho idealizado desde a gestação era de levar seu bebê para junto de si, logo após o nascimento.

Nesse pensar, torna-se importante que o enfermeiro e equipe interdisciplinar possam acolher essas mães, minimizando o medo vivenciado e preparando-as para receber esse bebê após a alta da UTIN.

\subsection{A PERCEPÇÃO DA MÃE EM RELAÇÃO AOS CUIDA- DOS PRESTADOS PELA EQUIPE DE ENFERMAGEM NA UNIDADE PEDIÁTRICA}

O envolvimento do profissional de enfermagem com a mãe é interpretado como uma atitude que faz com que ela sinta o apoio e acolhimento da equipe por meio de palavras que demonstrem afeto e carinho (PINHEIRO et al., 2009).

Durante o período que a criança permanece internada na Unidade Pediátrica surgem as dúvidas e as dificuldades, pois a mãe precisa cuidar do seu filho com todos os aparelhos que o acompanham.

Neste momento a equipe de enfermagem fazse essencial na oferta de apoio e autonomia à mãe, proporcionando um cuidar voltado ao binômio de forma integral e não apenas ao bebê na administração dos medicamentos, da dieta por sonda gástrica e realização do banho, minimizando assim a angústia da mãe.

Para Rosa, a ausência de apoio da equipe de enfermagem está relacionada às muitas tarefas desempenhadas pelos profissionais:

O enfermeiro tem um monte de coi-
sa pra fazer, os remédios e tudo. Ti-
nha uma lá que deixava muita coisa a
desejar, assim nessas horas acho que
depende muito do enfermeiro que
tá de plantão, que tem alguns que te
deixam calma, e alguns que te dei-
xam mais angustiada do que você já
tá! Tinha a questão de dá o leite no
copinho, algumas enfermeiras aju-
davam, outras não ajudavam, então
isso contava bastante (Rosa).

$\mathrm{O}$ apoio ofertado à mãe durante a internação do $\mathrm{RN}$ é primordial para que a vivência seja vista de forma positiva, para além da possibilidade de um processo interativo, da troca de experiências e resgate da humanização (GOMES et al., 2011).

A equipe de enfermagem é composta pelo enfermeiro e por técnicos de enfermagem que devem 
ser capacitados para a assistência de forma integral, contribuindo para que as dúvidas das mães sejam sanadas. No entanto, durante a vida profissional as ações são mecanizadas onde, muitas vezes, os profissionais deixam de atuar como facilitadores do aprendizado. Esta ausência de apoio é evidenciada por Orquídea e Primavera:

Um pouco de dificuldade que eu tive foi a questão da amamentação, na verdade ele não tava mamando né, mas a partir do momento que o meu leite começou a descer, eu não sabia como ordenhar, aí algumas pessoas da equipe se dispuseram ajudar, outras já deixavam mais aquém (Orquídea).

A enfermeira que às vezes ia no quarto e explicava algumas coisas, tirava algumas dúvidas mas as técnicas mesmo, elas não explicavam nada, tudo que sabíamos é porque tínhamos aprendido na UTI (Primavera).

O profissional de saúde deve estabelecer uma relação de confiança com as mães, de maneira que permita uma efetiva compreensão da mãe sobre a realidade vivida, contribuindo para o sucesso do tratamento e para a superação do momento de crise frente à hospitalização da criança (MOLINA et al., 2009).

Outro fator importante para que a assistência de enfermagem contemple as necessidades maternas é a formação de profissionais em atividades de educação continuada durante a graduação, focando na necessidade de articular com a mãe o cuidado da criança (FERNANDES; ANDRAUS; MUNARI, 2006).

Esta ausência de capacitação pode ser identificada no relato de Primavera:

Elas eram assim boas profissionais, profissionais muito boas, mas assim a impressão é que não tinham nem informação e conhecimento suficiente pra lidar com bebê em estado gravíssimo mesmo (Primavera).

Para tanto o enfermeiro deve proporcionar capacitação e treinamentos, subsidiando à equipe embasamento para assistência humanizada ao RN e também à mãe. Esta deve ser ensinada, orientada e supervisionada em todos os procedimentos que deverá realizar em seu filho.
No entanto é importante ressaltar que, além das técnicas e cuidados já citados, uma assistência realizada com dedicação e carinho, independente do turno de trabalho ou da carga horária exercida, reflete às mães o sentimento de acolhimento, de estar sendo bem assistida e amparada.

O profissional deve não apenas ser abastado de conhecimento, mas ter a consciência de que o compartilhar deste conhecimento torna o cuidado humanizado e colabora para a superação da mãe diante das circunstâncias, além de permear o vínculo e confiança entre a equipe de enfermagem e a mãe.

Eu fui muito bem amparada, algumas enfermeiras, eu notei que uma delas em específico, é um cuidado assim muito grande, uma prática com os bebês, um carinho enorme, então isso me dava uma segurança maior, principalmente quando era o plantão dela. Ela buscou a me ensinar a reaprender a dar banho, aos cuidados com a questão do umbiguinho né, que não precisava ter medo por causa do CAT ali do pescoço, que a cirurgia ela já tava bem cicatrizada, então assim ela tentou me dar o máximo de autonomia possível ali dentro pra mim me acostumar com aquela nova situação. Então eu achei assim muito bom o cuidado deles (equipe de enfermagem) (Tulipa).

É possível observar que outros autores, ao estudarem sobre as experiências e sentimentos das mães durante a hospitalização de seus filhos, afirmaram que a interação e o apoio da equipe de enfermagem são fatores fundamentais de aspecto facilitador no processo de enfrentamento (OLIVEIRA et al., 2013).

Em alguns momentos senti muita tristeza, chorei muito e me senti sozinha, mas logo passava porque minha filha estava sendo muito bem assistida (Tulipa).

Você vai pegando amizade com as enfermeiras e elas vão te ajudando. As enfermeiras lá ensinava com muita calma, paciência, porque mãe de primeira viagem acho que eles já entendem que tem muita dúvida, porque o tempo inteiro a hora que eles ia fazer medicação eu perguntava o que era que tava fazendo, porque tava fazendo (Margarida). 
Para além deste enfrentamento, as mães, tendo como prioridade o atendimento humanizado que favorece o fortalecimento de seu relacionamento com a equipe de enfermagem, diante da proximidade da alta do RN para casa, demonstram a necessidade do esclarecimento de suas dúvidas e do aprendizado para cuidar.

Eu tive apoio da equipe de enfermagem, bastante presente neste primeiro momento, perguntou se eu tinha dúvidas né, o primeiro banho foram eles que deram, foram elas que deram, sempre atenciosas, precisando de uma coisa sempre estavam próximas à gente tirando as dúvidas (Orquídea).

As enfermeiras que me ajudavam muito porque eu tinha medo de pegar, porque ela nasceu muito pequena, então eu não sabia como pegar, nem trocar uma fralda. Ela veio da UTI com o PIC, com acesso, só sondinha pra mamar que não porque na primeira noite ela já veio pro peito, pegou o peito de primeira. $\mathrm{O}$ primeiro banho foi uma enfermeira que deu pra me ensinar como dava e o segundo foi eu, e mesmo assim no segundo eu precisei de ajuda por causa do tamanho dela e o medo de pegar (Margarida).

O processo de assistência de enfermagem está intimamente ligado à orientação. Durante o atendimento o enfermeiro tem a oportunidade de passar conhecimentos básicos de cuidado que ajudem as mães a vencerem seus medos e seus anseios, superar seus limites e sentirem-se acalentadas diante dos momentos de angústia.

Não obstante, é preciso que o enfermeiro, em conjunto com a equipe de enfermagem, perceba e compreenda a mãe e o RN como uma unidade de cuidado, com enfoque voltado para a humanização.

\subsection{EXPERIENCIANDO O MOMENTO DE IR PARA CASA}

A alta hospitalar do RN é o momento incessantemente aguardado pela mãe, onde em seu íntimo surge uma mistura explosiva de sentimentos que permeiam a ansiedade, a alegria, a tranquilidade e o medo acompanhado de grandes expectativas para receber $o$ filho em casa, onde a mãe percebe a vulnerabilidade de seu bebê (FROTA et al., 2013).
A internação hospitalar do RN, independentemente do período, produz um aumento do nível de estresse materno que se inicia desde o período de permanência na UTIN, onde a mãe participa como visita em meio a tantas idas e voltas, até a alta para a Unidade Pediátrica, permanecendo como acompanhante e cuidadora de seu filho, longe do conforto de sua casa e do seio familiar.

Deste modo, foi possível observar o sentimento de alívio e expectativa na face de cada mãe durante seus relatos:

Eu já tava com a mala pronta, acho que de manhã que a médica falou olha qualquer coisa talvez amanhã, se elas estiverem bem a gente já dá alta, então chegou de manhã eu já fiz as malas já e contando os minutos pra dar o horário da visita médica pra poder ir embora porque eu não aguentava mais ficar dentro daquele hospital [...] parece que foi um ano, uma eternidade, eu tava muito estressada (Rosa).

Um alívio muito grande, muito grande porque o clima do hospital já tava muito tempo, a gente teve a questão da cirurgia, depois de passar por um período de visitas na neonatal né, de não poder pegar no colo, de amamentar, então quando ela saiu da neo que ela foi pro quanto, já foi uma alegria e quando teve alta aí sim a sensação que eu pude falar assim: "ela é minha mesmo", aquele alívio, aquela alegria né (Tulipa).

Frente à alta, prevalece um estado crítico influenciado pela necessidade da integridade do cuidado, onde a mãe apresenta dúvidas e insegurança aos cuidados básicos e a possibilidade de cuidados especiais (NIETSCHE et al., 2012). Neste pensar, a mãe busca amparo profissional com a intenção de minimizar o medo dos cuidados a serem realizados por ela em casa:

A gente se preparou pra vir pra casa, porque sabe marinheiros de primeira viagem e com dois, aí a gente chamou uma enfermeira do berçário lá pra ficar os primeiros dias aqui pra ajudar nos cuidados [...] é assim, é que sempre é aquela dupla sensação, por um lado era um alívio de sair do hospital e por outro 
era uma preocupação de volta pra casa, porque no hospital você tem todo um aparato, mesmo que não funcione cem por cento, mas você sabe que qualquer coisa você grita e alguém aparece, quando o bebê se afoga por exemplo, e em casa não, a hora que só tá você lá com as duas crianças e aí se acontece alguma coisa, entendeu, então batia aquele medo de volta pra casa e não saber o que fazer, porque eu né mãe pela primeira vez, malemá eu sabia como segurar a criança, dá um banho, sabe (Rosa).

Ele não pegou no peito lá, ele veio pegar no peito agora com 40 dias de nascimento, ele tinha muita dificuldade, ele não abocanhava por ser prematuro a boquinha é pequena ele não abocanhava, então precisei de ajuda do banco de leite pra fazer a pega. A experiência foi angustiante, pensei várias vezes em desistir, não aguentava mas deu certo (Orquídea).

As atividades exercidas pela mãe durante a internação do RN na Unidade Pediátrica representam a reestruturação do papel materno de alimentar e cuidar do filho, além de estabelecer um sentimento autoconfiante de que as dificuldades serão superadas (SOUZA et al., 2009).

À medida que a mãe cuida do seu filho na Unidade Pediátrica, novas dúvidas vão surgindo, principalmente em relação a como será este cuidado em casa, pois sabem que o bebê está próximo de receber alta. É através do surgimento destas dúvidas que elas apreendem as orientações realizadas pela equipe de enfermagem.

Fica evidente, no depoimento de Margarida, as dúvidas e anseios diante da expectativa de como será cuidar do filho em casa:

Mas a maior dúvida foi de quando eu viesse pra casa, o que eu ia fazer com uma criança de $41 \mathrm{~cm}$, o que eu ia fazer, como que eu ia cuidar, cuidado básico, sem vacina nenhuma, tava frio o tempo, minha maior dúvida foi essa (Margarida).

Gerenciar o cuidado e orientar as mães proporcionando a elas autonomia com o bebê após a alta são medidas realizadas pelos enfermeiros que permeiam a continuidade da assistência (BRAGA; SENA, 2012).
Orquídea e Tulipa enfatizam a importância de informações que preparam as mães para a alta do RN:

\begin{abstract}
Elas me prepararam certinho, passaram todas as informações, a questão do banho né, do cuidado com a pele, fizeram todo procedimento básico pra saída, foi tranquilo assim a orientação[...] (Orquídea).

Sim, as orientações foi tudo que eu precisava, eles me deixaram bem tranquila, assim muitas enfermeiras veio conversar comigo, me explicar que não precisava ter medo sabe, me ajudar, a questão por que [...] até porque no começo, eu já tinha o primeiro, mas eu tinha medo até de trocar fralda (Tulipa).
\end{abstract}

Assim, a assistência de enfermagem reflete no fortalecimento do vínculo mãe/RN/enfermeiro, contribuindo para a integralidade do cuidado à criança por meio da educação continuada que prepara a mãe para superar o medo e receber seu filho no âmago da família com confiança e alegria.

\section{CONSIDERAÇÕES FINAIS}

A experiência de internação de um filho em UTIN após o nascimento produz nas mães um sentimento de perda e impotência. Frente ao distanciamento entre o binômio mãe/filho ocorre uma desestruturação no que se refere aos primeiros cuidados que seriam realizados pela mãe.

O estudo desvelou um contraste de sentimentos vividos pelas mães diante da alta da UTIN, onde, apesar do alívio e alegria de poder estar perto do filho na Unidade Pediátrica, elas também sentiram angústia, medo e impotência perante a necessidade de cuidar de uma criança aparentemente frágil.

Diante da assistência prestada pela equipe de enfermagem ao RN e das orientações realizadas em relação ao cuidado observou-se uma divergência de sentimentos. Algumas demonstraram plena satisfação, enquanto outras revelaram insatisfação em relação ao cuidado com ênfase na ausência de capacitação profissional para fornecer orientações esclarecedoras. 
Em relação ao vínculo mãe/profissional de enfermagem percebeu-se, pelos relatos, que nem todas as mães conseguiram estabelecer uma relação plena de confiança com o profissional de enfermagem, o que indica uma lacuna no processo de assistência.

Neste pensar, observa-se a importância do gerenciamento da assistência de enfermagem, realizada pelo profissional enfermeiro com o intuito de orientar e capacitar as mães para o cuidado com o filho após a alta da Unidade Pediátrica.

Sendo assim, perante os resultados alcançados, o presente estudo busca instrumentalizar os profissionais enfermeiros com o objetivo de contribuir para o processo de humanização da assistência de enfermagem.

\section{REFERÊNCIAS}

ANJOS, L. S. dos; LEMOS, D. M.; ANTUNES, L, A.; ANDRADE, J. M. O.; NASCIMENTO, W. D. M.; CALDEIRA, A. P. Percepções maternas sobre o nascimento de um filho prematuro e cuidados após a alta. Rev. bras. enferm., v. 65, n. 4, p. 571-577, 2012. Disponível em: < http://www. scielo.br/pdf/reben/v65n4/a04v65n4.pdf $>$. Acesso em: 10 out. 2014.

ARAÚJO, B. B. M.; RODRIGUES, B. M. R. D. Vivências e perspectivas maternas na internação do filho prematuro em unidade de tratamento intensivo neonatal. Rev. Esc. Enferm. USP, v. 44, n. 4, p. 865-872, 2010. Disponível em: $\quad<$ http://www.scielo.br/scielo.php?script $=$ sci pdf\&pid $=$ S0080-62342010000400002\&lng $=$ en\&nrm $=$ iso\&tlng $=\mathrm{pt}>$. Acesso em: 25 fev. 2014.

BARDIN, L. Análise de conteúdo. Lisboa, Portugal: Edições 70, 1978.

BRAGA, P. P.; SENA, R. R.Estratégias para efetivar a continuidade do cuidado pós-alta ao prematuro: revisão integrativa. Acta paul. enferm., v. 25, n.6, p. 975-980, 2012. Disponível em: <http://www.scielo.br/pdf/ape/ v25n6/v25n6a23.pdf > . Acesso em: 27 out. 2014.

DUARTE, E. D.; SENA, R. R.; XAVIER, C. C. A vivência de pais e profissionais na unidade de terapia intensiva neonatal. Rev. Ciência y Enfermeria, v. 17, n. 2, p.
77-86, 2011. Disponível em: <http://www.scielo.cl/pdf/ cienf/v17n2/art_09.pdf $>$. Acesso em: 23 out. 2014.

FERNANDES, C. N. S.; ANDRAUS, L. M. S.; MUNARI, D. B. O aprendizado do cuidar da família da criança hospitalizada por meio de atividades grupais. Rev. Eletr. Enf., v. 8, n. 1, p. 108-118, 2006. Disponível em: < http:// www.fen.ufg.br/revista/revista8_1/original_14.htm $>$. Acesso em: 23 out. 2014.

FLICK, U. Introdução à pesquisa qualitativa. 3. ed. Porto Alegre: Artmed, 2009.

FROTA, M. A.; SILVA, P. F. R. da; MORAES, S. R. de; MARTINS, E. M. C. S.; CHAVES, E. M. C.; SILVA, C. A. B. da. Alta hospitalar e o cuidado do recém-nascido prematuro no domicílio: vivência materna. Esc. Anna Nery., v. 17, n. 2, p. 277-283, 2013. Disponível em: <http://www. scielo.br/pdf/ean/v17n2/v17n2a11.pdf $>$. Acesso em: 26 out. 2014.

GAIVA, M. A. M. O cuidar em unidades de cuidados intensivos neonatais: em busca de um cuidado ético e humanizado. Rev. Cogitare Enferm. v. 4, n. 1, p. 61-66, 2006. Disponível em: <http://ojs.c3sl.ufpr.br/ojs/index. php/cogitare/article/view/5976/4276>. Acesso em: 10 out. 2014.

GIL, A. N. Como elaborar projetos de pesquisa. 5. ed. São Paulo: Atlas, 2010.

GOMeS, G. C.; PINTANEL, A. C.; STRASBURG, A. C.; ERDMANN, A. L. O Apoio Social ao Familiar Cuidador Durante a Internação Hospitalar da Criança. Rev. Enferm. UERJ, Rio de Janeiro, v. 19, n. 1, p. 64-69, 2011. Disponível em: < http://www.facenf.uerj.br/v19n1/ v19n1a11.pdf $>$. Acesso em: 23 out. 2014.

MOLINA, R.C.M.; FONSECA, E. L.; WAIDMAN, M. A. P.; MARCON, S. S. A percepção da família sobre sua presença em uma Unidade de Terapia Intensiva Pediátrica e Neonatal. Rev. Esc. Enferm. USP, v. 43, n. 3, p. 630-638, 2009. Disponível em: <http://www.scielo.br/pdf/reeusp/ v43n3/a19v43n3.pdf> . Acesso em: 23 out. 2014.

NIETSCHE, E. A.; NORA, A. D.; LIMA, M. G. R. de; BOTTEGA, J. C.; NEVES, E. T.; SOSMAYER, V. L. Educação 
em saúde: planejamento e execução da alta em uma Unidade de Terapia Intensiva neonatal. Esc. Anna Nery, v. 16 , n. 4, p. $809-816$, 2012. Disponível em: < http:// www.scielo.br/pdf/ean/v16n4/24.pdf $>$. Acesso em: 26 out. 2014.

OLIVEIRA, K.de; VERONEZ, M.;HIGARASHI,I.H.;CORRÊA, D. A. M. Vivências de familiares no processo de nascimento e internação de seus filhos em UTI neonatal. Esc. Anna Nery, v. 17, n. 1, p. 46-53, 2013. Disponível em: <http:// www.scielo.br/readcube/epdf.php?doi $=10.1590 /$ S $1414-81452013000100007 \&$ pid $=S 1414$ $81452013000100007 \&$ pdf_path $=$ ean/v17n1/07.pdf $>$. Acesso em: 23 out. 2014.

PINHEIRO, E. M.; BALBINO, F. S.; BALIEIRO, M. M. F. G.; DOMENICO, E. B. L. De; AVENA, M. J. Percepção da Família do Recém-Nascido Hospitalizado sobre a Comunicação de Más Notícias. Rev. Gaúcha Enferm, Porto Alegre, v. 30, n. 1, p. 77-84, 2009. Disponível em: $<$ http://seer.ufrgs.br/RevistaGauchadeEnfermagem/ article/view/5345/6566>. Acesso em: 19 out. 2014.

RODRIGUES, L. M.; MOREIRA, P. L. Tornar-se pai vivenciando a internação do filho em Unidade de Terapia Intensiva Neonatal. J Health Sci Inst., v. 30, n. 2, p. 227-230, 2012. Disponível em: <http://www.unip.br/ comunicacao/publicacoes/ics/edicoes/2012/03_jul-set/ V30_n3_2012_p227a230.pdf > . Acesso em: 24 fev. 2014.

SALES, C.A.; ALVES, N. B.; VRECCHI, M. R.; FERNANDES, J. Concepção das Mães Sobre os Filhos Prematuros em UTI. Rev Bras Enferm, v. 59, n. 1, p. 20-24, 2006. Disponível em: <http://www.scielo.br/pdf/reben/v59n1/ a04v59n1.pdf>. Acesso em: 27 set. 2013.

SOUZA, N. L.; ARAÚJO, A. C. P. F.; COSTA, I. C. C.; CARVALHO, J. B. L.; SILVA, M. L. C. Representações de mães sobre hospitalização do filho prematuro. Rev. bras. enferm., v. 62, n. 5, p. 729-733, 2009. Disponível em: $\quad<$ http://www.scielo.br/pdf/reben/v62n5/13.pdf > . Acesso em: 15 mar. 2014.

SOUZA, J. C.; SILVA, L. M. S.; GUIMARÃES, T. A. Preparo para a alta hospitalar de recém-nascido em unidade de tratamento intensivo neonatal: uma visão da família.
Pediatria, São Paulo, v. 30, n. 4, p. 217-227, 2008. Disponível em: <http://www.pediatriasaopaulo.usp.br/ upload/pdf/1268.pdf>. Acesso em: 17 out. 2014.

Recebido em: 01 junbo 2015

Revisado em: 11 fevereiro 2016

Aceito em: 29 fevereiro 2016 